University of Nebraska - Lincoln

DigitalCommons@University of Nebraska - Lincoln

2013

\title{
Narrative text analysis to identify technologies to prevent motor vehicle crashes: Examples from military vehicles
}

\author{
Keshia M. Pollack \\ Johns Hopkins Bloomberg School of Public Health, kpollack@jhsph.edu \\ Nathan Yee \\ University of California School of Medicine \\ Michelle Canham-Chervak \\ U.S. Army Public Health Command \\ Lauren Rossen \\ Centers for Disease Control and Prevention \\ Kathleen E. Bachynski \\ Columbia University Mailman School of Public Health \\ See next page for additional authors
}

Follow this and additional works at: https://digitalcommons.unl.edu/usarmyresearch

Pollack, Keshia M.; Yee, Nathan; Canham-Chervak, Michelle; Rossen, Lauren; Bachynski, Kathleen E.; and Baker, Susan P., "Narrative text analysis to identify technologies to prevent motor vehicle crashes:

Examples from military vehicles" (2013). US Army Research. 212.

https://digitalcommons.unl.edu/usarmyresearch/212

This Article is brought to you for free and open access by the U.S. Department of Defense at DigitalCommons@University of Nebraska - Lincoln. It has been accepted for inclusion in US Army Research by an authorized administrator of DigitalCommons@University of Nebraska - Lincoln. 


\section{Authors}

Keshia M. Pollack, Nathan Yee, Michelle Canham-Chervak, Lauren Rossen, Kathleen E. Bachynski, and Susan P. Baker 


\title{
Narrative text analysis to identify technologies to prevent motor vehicle crashes: Examples from military vehicles ${ }^{2}$
}

\author{
Keshia M. Pollack a,*, Nathan Yee ${ }^{\text {b, } 1}$, Michelle Canham-Chervak ${ }^{c}$, Lauren Rossen ${ }^{\text {d,2 }}$, \\ Kathleen E. Bachynski ${ }^{\mathrm{e}, 3}$, Susan P. Baker ${ }^{\text {a }}$ \\ a Johns Hopkins Bloomberg School of Public Health, Johns Hopkins Center for Injury Research and Policy, Department of Health Policy and Management; 624 N Broadway, \\ Baltimore MD 21205, USA \\ ${ }^{\mathrm{b}}$ University of California School of Medicine, USA \\ c U.S. Army Public Health Command, Injury Prevention Program, E5158 Blackhawk Road, Aberdeen Proving Ground, MD 21010-5403, USA \\ ${ }^{d}$ National Center for Health Statistics, Centers for Disease Control and Prevention, 3311 Toledo Rd, Hyattsville, MD 20782, USA \\ e Columbia University Mailman School of Public Health, Department of Sociomedical Sciences, 722 West 168th Street, New York, NY 10032, USA
}

\section{A R T I C L E I N F O}

Available online 20 November 2012

\section{Keywords:}

Narrative text analysis

Motor vehicle

Technology

U.S. Army

Occupational injury

\begin{abstract}
A B S T R A C T
Introduction: The purpose of this research is to describe the leading circumstances of military vehicle crashes to guide prioritization and implementation of crash avoidance and/or warning technologies. Methods: A descriptive study using narrative text analysis on 3,944 military vehicle crash narratives. Crash data on drivers, from 2001 to 2006, were assembled from the U.S. Army Combat Readiness/Safety Center. Reviewers collected information on the circumstances of crashes and determined if vehicle technology could have prevented the crash. Results: Nearly $98 \%$ of the crashes were nonfatal; $63 \%$ occurred in the U.S. and $24 \%$ in Iraq. Among crash events where the direction of the impact was recorded, $32 \%$ were to the front of the vehicle and $16 \%$ involved a vehicle being rear-ended. Rollovers were mentioned in $20 \%$ of the narratives. Technology was determined to have the potential to prevent $26 \%$ of the crashes, with the forward collision warning system, rear end collision avoidance, emergency brake assistance, and rollover stability control system likely to have the greatest impacts. Conclusions: Some technologies available for civilian vehicles may prevent certain military crash circumstances. Impact on Industry: The results of this research are significant in light of ongoing global military operations that rely on military vehicles. Improving the preventive technology featured on military vehicles may be an effective strategy to reduce the occurrence of military crashes.
\end{abstract}

(c) 2013 National Safety Council and Elsevier Ltd. All rights reserved.

\section{Introduction}

Motor vehicle crashes (MVCs), involving both privately owned and military vehicles, are a leading cause of serious injury and non-combat fatalities among military populations (Angello \& Smith, 2010; Armed Forces Health Surveillance Center, 2011; Jones, Canham-Chervak, Canada,

\footnotetext{
is This publication was funded by the Defense Safety Oversight Council through the Concurrent Technologies Corporation in 2008-2009. It was also supported by Grant Number 5R49CE001507 from the Centers for Disease Control and Prevention to the Johns Hopkins Center for Injury Research and Policy. The views expressed in this publication are those of the authors and should not be construed to represent the positions of the Centers for Disease Control and Prevention, the Department of the Army, or the Department of Defense.

* Corresponding author at: Johns Hopkins University, 624 N. Broadway, Room 557, Baltimore, MD 21205-1996.

E-mail address: kpollack@jhsph.edu (K.M. Pollack).

${ }^{1}$ Work was completed when Mr. Yee was employed at the Johns Hopkins Center for Injury Research and Policy.

2 This research was completed while Dr. Rossen was a PhD student at Johns Hopkins Bloomberg School of Public Health.

${ }^{3}$ This work was completed while Ms. Bachynski was a fellow at the U.S. Army Public Health Command.
}

Mitchener, \& Moore, 2010). Between 1999 and 2006 there were approximately 11,500 reports of crashes involving privately owned and military vehicles, including motorcycles, among active duty Army personnel (Rossen, Pollack, Canham-Chervak, Canada, \& Baker, 2011). Roughly $10 \%$ of these crashes resulted in a fatality and $36 \%$ resulted in a lost workday (Rossen et al., 2011). Conservative estimates using cause-coded injury data from U.S. Army medical surveillance suggest that annually there are 6,000-8,000 inpatient and outpatient medical encounters among Soldiers for MVCs (Dada, Canham-Chervak, \& Jones, 2010). MVCs are also one of the leading causes of injury-related hospitalization in the U.S. Army (Dada-Laseinde, Canham-Chervak, \& Jones, 2009).

While many studies of military MVCs combine privately owned and military vehicles, research has supported separately analyzing these vehicles because of differences in vehicle design and operating environment, which influence prevention strategies (Krahl, Jankosky, Thomas, \& Hooper, 2010). Prior research also indicates that a majority of crashes reported to the U.S. Army Combat Readiness/Safety Center between 1999 and 2006 involved military vehicles rather than privately owned vehicles (Rossen et al., 2011). A systemic review by Krahl, Jankosky, Thomas, and Hooper (2010) evaluated research that has specifically explored 
military MVCs and reported a dearth of research in this area. In addition to calling for more research, Krahl et al. (2010) noted that crash avoidance safety technologies are available for civilian automobiles, and they suggested that application of these existing technologies to military vehicles should be considered, ideally during the vehicle design stage.

Several agencies, including the Insurance Institute for Highway Safety (IIHS) and National Highway Traffic Safety Administration (NHTSA), have taken action to improve vehicle safety by encouraging the development, testing, and use of technologies such as forward collision warning systems to prevent crashes (Insurance Institute for Highway Safety, 2008; National Highway Traffic Safety Administration, 2011). These technologies have been tested and are available on a growing number of luxury and less costly vehicles (Insurance Institute for Highway Safety, 2008). The U.S. Army has also considered implementing technology to prevent crashes. In order to guide decision-making regarding which safety technologies to prioritize for potential implementation on military vehicles, a narrative text analysis was conducted to describe the leading crash circumstances and determine if technology could have prevented the crash.

\section{Methods}

\subsection{Design}

This descriptive study used narrative text analysis to extract detailed information from safety reports on MVCs sustained by Army personnel. This method was chosen because it affords an in-depth examination of the circumstances of incidents, especially for factors not captured by standardized coding schemes (Lincoln et al., 2004; McKenzie, Scott, Campbell, \& McClure, 2010). This research, based on data without personal identifiers, was classified as exempt by the Johns Hopkins Bloomberg School of Public Health Institutional Review Board.

\subsection{Data source}

Data for this analysis originated from a larger epidemiologic study of MVCs (privately owned and military vehicles, including motorcycles) in the U.S. Army. In 2008 we obtained from the Army Safety Management Information System (ASMIS) data on all crashes that occurred from 1999 to 2006. The U.S. Army Combat Readiness/Safety Center (ACR/SC) maintains the ASMIS, which comprehensively details crashes involving Army personnel. All incidents reported to the ACR/ SC are recorded in this database. Reports are submitted to ACR/SC by unit safety officers, who are responsible for completing the requisite forms and conducting interviews with witnesses and survivors of each crash. The ASMIS database includes safety reports on crashes involving privately owned vehicles, military vehicles, motorcycles, and other types of vehicles in use by Army personnel. It also includes information on vehicle incidents that involve general damage to vehicles, such as those from hail or fire.

For this present analysis, conducted in 2010, we received narrative reports which we linked to the existing crash reports used in the larger quantitative study. We removed reports for passengers (a crash report is prepared for each person involved in a crash) and all non-military vehicles. We also limited the sample to crashes that occurred between 2001 and 2006, which corresponded with the start of Operation Enduring Freedom in Afghanistan and represents a period during which U.S. Forces were training for combat operations in Afghanistan, and beginning in 2003, Iraq. These exclusions resulted in 4,365 unique reports. An additional 421 reports were removed because of insufficient information for abstraction of narrative text data, or if there was a fatality or injury but no crash (e.g., vehicle fire), or if there was vehicle damage, but no crash (e.g., hail damaged the vehicle). The remaining 3,944 narratives comprised the sample used in this analysis.

\subsection{Narrative data abstraction and analysis}

To determine the variables that would be abstracted from the narratives we focused on factors that would result in a crash or contribute to likelihood of its occurrence, versus crash-related factors that would lead to injury once a crash occurs. Initially, a list of determinants of crashes was assembled drawing on existing knowledge. Next, a random sample of $10 \%$ of the 3,944 narratives was read and additional key variables specific to military settings were identified. Finally, a group of experts reviewed the list of key variables to confirm it was comprehensive.

The final list of variables included: crash factors (date, time of day, country, direction and circumstances of crash); driver factors (total hours of continuous duty, fatality, seatbelt availability and use, presence of passenger); vehicle type and condition; and environmental factors (road conditions, weather, visibility). Vehicle type was defined using a definition consistent with U.S. Army safety regulations (Department of the Army, 1994). Army motor vehicles were defined as any vehicle that is owned, leased, or rented by the Army that is primarily designed for over-the-road operation and whose general purpose is transportation of cargo or personnel. Examples include High Mobility Multipurpose Wheeled Vehicles (HMMWVs), Heavy Expanded Mobility Tactical Trucks (HEMTTs), and other select tactical and commercial vehicles. Army combat vehicles were defined as vehicles primarily used for combat, such as tanks, self-propelled weapons, and tracked armored personnel carriers. As stated in Department of the Army Pamphlet 385-40, "combat is defined as an incident in a theater of hostile fire or enemy action, but not as the result of such fire/action. This includes direct preparation for combat, actual combat, or redeployment from a combat theater immediately following combat." Thus, for this analysis, injuries due to direct enemy fire were not included, but crashes that occurred in a combat setting were included.

The list of potential technologies was developed based on a review of the extant literature and documents from the military (Hanna, 2007; Insurance Institute for Highway Safety, 2008; Oak Ridge National Laboratory, 2001; Oesch, 2009; Rice, 2008), and included anti-lock brakes; emergency brake assistance; drowsy/distracted driver detection and warning, drunk driver warning, adaptive highlights, forward collision warning, rear-end collision avoidance, lane departure warning, blind spot detection, back-up alarms, intersection collision avoidance, speed adaptation system, stability control system, and black ice warning systems. Each of the reviewers used the details of the crash circumstances and technology descriptions to determine whether technology could have prevented the crash. If technology could have potentially prevented the crash, reviewers also determined which technologies could have prevented the crash. Several technologies could be chosen for each crash event, and the selection of the specific technology was made by looking at a matrix created by the lead investigator that matched various crash circumstances to technologies. Reviewers were able to select "other technology" if they determined that technology other than what was on the list might prevent a crash. In those cases where "other technology" was chosen, the reviewer described the ideal function of the technology given a specific crash circumstance.

A web-based data abstraction tool was used as it allowed for systematic data collection with multiple reviewers (SurveyMonkey, 2011). Reviewers extracted information on crash circumstances by identifying the primary cause of the crash, from the perspective of the driver for the vehicle that was the focus of each narrative. For example, if a vehicle was reported as backing up and crashed into a wall, the circumstance of the crash was categorized as a "rear crash with a non-moving object." If the information for a variable was not in the narrative, then it was coded as missing.

Prior to beginning the narrative review, three public health scientists received a significant amount of training from the study's lead investigator, and a data dictionary and narrative review guidelines were distributed. A random sample of $n=30$ narratives was selected for each rater to review in order to determine agreement for all of the 
variables between the raters. The results from the Kappa statistic $(0.90$, $\mathrm{p}<0.01)$ revealed that agreement between raters exceeded chance levels. The remaining narrative cases were distributed among the reviewers. After data abstraction was complete, the lead study investigator reviewed $10 \%$ of the narratives and confirmed the results; no discrepancies were found.

\section{Results}

\subsection{Description of crashes}

Approximately $93 \%$ of the 3,944 crashes captured in the narratives between 2001 and 2006 involved an Army motor vehicle (Table 1). Army

Table 1

Description and Circumstances of Vehicle Crashes Reported to the U.S. Army Safety Center (Drivers only), 2001-2006 $(n=3,944)$.

\begin{tabular}{|c|c|c|}
\hline Variables & & $\mathrm{N}(\%) *$ \\
\hline \multirow[t]{2}{*}{ Fatal crash } & Yes & $83(2.0)$ \\
\hline & No & $3,856(98.0)$ \\
\hline \multirow[t]{3}{*}{ Vehicle Type } & Army motor & $3,680(93.0)$ \\
\hline & Army combat & $224(6.0)$ \\
\hline & Other military vehicle & $40(1.0)$ \\
\hline \multirow{6}{*}{$\begin{array}{l}\text { Country where } \\
\text { crash occurred }\end{array}$} & United States & $2,501(63.0)$ \\
\hline & Iraq & $935(24.0)$ \\
\hline & Germany & $195(5.0)$ \\
\hline & South Korea & $2.6(<1.0)$ \\
\hline & Kuwait & $1.8(<1.0)$ \\
\hline & Afghanistan & $45(1.0)$ \\
\hline \multirow{3}{*}{$\begin{array}{l}\text { Time of day crash } \\
\text { occurred }\end{array}$} & Daylight & $3,009(76.0)$ \\
\hline & Dusk & $838(21.0)$ \\
\hline & Night & $79(2.0)$ \\
\hline \multirow{5}{*}{$\begin{array}{l}\text { Direction of the crash } \\
\text { (primary vehicle) }\end{array}$} & Front & $1,266(32.1)$ \\
\hline & Rear & $410(10.4)$ \\
\hline & Side & $471(12.0)$ \\
\hline & Other & $1,106(28.1)$ \\
\hline & Missing & $686(17.4)$ \\
\hline \multirow{7}{*}{$\begin{array}{l}\text { Leading crash } \\
\text { circumstances** }\end{array}$} & Struck a non moving object & $976(24.8)$ \\
\hline & Roll-over/overturn & $763(19.7)$ \\
\hline & Ran off road & $762(19.3)$ \\
\hline & Rear-ended another vehicle & $641(16.3)$ \\
\hline & $\begin{array}{l}\text { Struck by another vehicle } \\
\text { (not rear ended) }\end{array}$ & $582(14.8)$ \\
\hline & Skidded & $496(12.6)$ \\
\hline & Struck a moving object & $497(12.6)$ \\
\hline $\begin{array}{l}\text { Road conditions/road } \\
\text { environment contributed } \\
\text { to the crash** }\end{array}$ & Yes & $1,265(32.1)$ \\
\hline \multirow[t]{8}{*}{ Type } & Intersection & $335(26.4)$ \\
\hline & Tight curve & $136(10.7)$ \\
\hline & Rocky/rough terrain & $128(10.1)$ \\
\hline & Incline/steep road & $97(7.7)$ \\
\hline & Hilly & $59(4.7)$ \\
\hline & Winding & $42(3.2)$ \\
\hline & Slippery (not due to precipitation) & $56(4.4)$ \\
\hline & No & $2,672(67.9)$ \\
\hline $\begin{array}{l}\text { Inclement weather } \\
\text { contributed to } \\
\text { the crash*** }\end{array}$ & Yes & $573(14.6)$ \\
\hline \multirow[t]{6}{*}{ Type } & Rain/storm & $203(35.3)$ \\
\hline & Ice & $175(30.4)$ \\
\hline & Fog/mist & $82(14.3)$ \\
\hline & Dust & $120(20.9)$ \\
\hline & Snow/sleet/hail & $110(19.1)$ \\
\hline & No & $3,364(85.4)$ \\
\hline \multirow{2}{*}{$\begin{array}{l}\text { Vehicle condition } \\
\text { contributed } \\
\text { to the crash }\end{array}$} & Yes & $409(10.4)$ \\
\hline & No & $3,528(89.6)$ \\
\hline
\end{tabular}

* Percents may not add to 100 because of missing data or unknown answers.

** Multiple responses could have been selected. combat vehicles accounted for only $6 \%$ of the crashes. Nearly all of the crash events were nonfatal (98\%). Approximately $63 \%$ of the crashes occurred in the U.S. and 24\% occurred in Iraq. Distribution of crashes differs significantly by vehicle type, with more crashes in the U.S. involving Army motor vehicles, and more crashes in Iraq involving Army combat vehicles. Road conditions, including the presence of potholes or rocky terrain, were mentioned in $32 \%$ of the crashes. Most (76\%) of the crashes occurred during daylight hours. Of the nearly $15 \%$ of the narratives that mentioned weather being a contributing factor, the leading types of inclement weather involved precipitation. Adverse road conditions were mentioned in about $32 \%$ of the narratives, of which the presence of an intersection, rocky/rough terrain, or a tight curve, were most often listed. Vehicle defects were only mentioned in $10 \%$ of the crashes.

When direction of crash was mentioned, $32 \%$ involved a front collision. Over half of the crashes where direction of the crash was listed as 'other' involved a vehicle rolling over or running off the road. Roughly $25 \%$ of the crashes involved a vehicle that struck a non-moving object. In $20 \%$ of the crashes the vehicle rolled over and in $19 \%$ of the crashes the vehicle ran off of the road. The primary vehicle rear-ended another vehicle in $16 \%$ of the crashes and in $15 \%$ of the crashes the primary vehicle was hit, but not rear-ended by another vehicle. The vehicle skidded in nearly $13 \%$ of the crashes and reportedly struck a moving object in $13 \%$ of the crashes.

\subsection{Technology assessment}

There was a strong likelihood that technology could have prevented at least $26 \%$ of the crashes $(n=1,002)$ (Table 2$)$. In $34 \%$ of the crashes, the reviewers were unsure if technology could have prevented the crash and in $40 \%$ of the cases the effect of technology in preventing the crash seemed unlikely. These cases where technology was determined not to influence a crash were also the same crashes where human error was noted as being a strong factor in the crash (i.e., narrative mentioned Soldier error).

Since a large proportion of the crashes involved forward collisions, the forward collision warning system would most likely prevent the greatest number of crashes. Many of these forward collisions involved a military vehicle colliding with a nonmoving object or another vehicle, circumstances possibly amenable to a forward collision warning system. Rear collision warning systems are also able to provide similar protection and were determined to be relevant for many of these collisions as well. Crashes where a vehicle in reverse struck another vehicle or an object are also possibly amenable to specific types of rear end collision warning systems, such as rear cameras or backup alarms.

Emergency brake assistance technology is designed to increase braking power by maximizing braking pressure, regardless of how forcefully the driver actually engages the pedal in order to decrease stopping distances. This technology was identified with the potential to prevent at least $24 \%$ of the crashes, particularly those where the primary vehicle collided with a moving vehicle and did not stop in time. Several narratives described distracted drivers who did not realize the distance to the vehicle ahead, or situations where the vehicle ahead stopped suddenly. Crashes resulting from these circumstances could be prevented with emergency brake assistance and collision warning systems (CWS). Stability control systems are used to guide a vehicle back to the driver's intended direction and to prevent the vehicle from rolling over. This technology may help prevent the rollovers mentioned in $20 \%$ of the narratives. Several other technologies were assessed and have potential to prevent some crashes, but far fewer than the prior four technologies described (Table 2).

\section{Discussion}

These results support the potential role of technology to prevent at least $26 \%$ of the crashes, with the forward collision warning system, 
Table 2

Applicable Existing Technologies and Preventable Crashes Reported to the U.S. Army Safety Center (Drivers only), 2001-2006 ( $\mathrm{n}=1,002$ ).

\begin{tabular}{|c|c|c|c|}
\hline $\begin{array}{l}\text { Potentially applicable } \\
\text { technologies* }\end{array}$ & Purpose & $\begin{array}{l}\text { Percent of } \\
\text { crashes }(\%)\end{array}$ & $\begin{array}{l}\text { Number of } \\
\text { crashes** }\end{array}$ \\
\hline Forward collision warning & $\begin{array}{l}\text { In-vehicle electronic systems that monitor the roadway in front of the host vehicle and warn the driver when a } \\
\text { potential collision risk exists }\end{array}$ & 34 & 788 \\
\hline Emergency brake assistance & Automatically enhances effort to decrease stopping distance when 'panic braking' is detected & 24 & 560 \\
\hline Rear end collision avoidance & $\begin{array}{l}\text { System that automatically causes a vehicle to brake by itself if the driver doesn't when a rear-end collision with } \\
\text { another object or vehicle is imminent. }\end{array}$ & 21 & 490 \\
\hline Stability control system & $\begin{array}{l}\text { The system intervenes when a loss of steering control is detected and makes a series of adjustments to guide a } \\
\text { vehicle back to the driver's intended direction or prevent the vehicle from rolling over. }\end{array}$ & 20 & 457 \\
\hline Blind spot detection & System that aids drivers in detecting objects or vehicles in their blind spots. & 9 & 210 \\
\hline $\begin{array}{l}\text { Drowsy/distracted driver } \\
\text { detection \& warning }\end{array}$ & $\begin{array}{l}\text { Monitors physical characteristics or behaviors of driver that indicate distraction/drowsiness such as eye } \\
\text { movement or mouth shape (yawning). Additionally often provides some kind of tactile, visual, or auditory } \\
\text { warning when distracted driving is detected. }\end{array}$ & 8 & 193 \\
\hline $\begin{array}{l}\text { Intersection collision } \\
\text { avoidance }\end{array}$ & $\begin{array}{l}\text { Systems that use sensors to gather information about vehicle movements near an intersection, process that } \\
\text { information to determine if a collision is at risk of occurring, and issue warnings to drivers of vehicles in danger. }\end{array}$ & 8 & 193 \\
\hline Speed adaptation system & $\begin{array}{l}\text { Warns the driver and/or automatically limits the speed of the vehicle when the vehicle is traveling over the } \\
\text { posted speed limit. }\end{array}$ & 8 & 178 \\
\hline Anti-lock brakes & $\begin{array}{l}\text { Prevents wheels from locking while braking. Allows driver to maintain steering control under heavy breaking } \\
\text { conditions by preventing skidding. }\end{array}$ & 8 & 176 \\
\hline Lane departure warning & System that warns a driver when the vehicle begins to move out of its lane. & 6 & 142 \\
\hline Adaptive headlights & Headlights turn in the direction of the road ahead including curves and hills to increase visibility. & 5 & 112 \\
\hline Back-up alarms & System that alerts driver if there is a risk of hitting an object or vehicle while backing up. & 4 & 82 \\
\hline Black ice warning systems & System that is able to detect the presence of black ice in the road ahead and subsequently warn the driver & 2 & 56 \\
\hline
\end{tabular}

* This information was summarized from NHTSA, IIHS, DELPHI $89,9,14,15,18$.

** Cases are not mutually exclusive.

rear end collision avoidance, emergency brake assistance, and rollover stability control system likely to have the greatest impacts.

Research on the effectiveness of these technologies is largely limited to privately owned vehicles, specifically, more high-end vehicles. Only one account was found in the existing literature where crash avoidance technology was applied to military vehicles and then evaluated. A 2001 report by NTSB on CWS mentioned that: "In 1995, the U.S. Army tested a CWS on six convoy vehicles traveling throughout the U.S. and nine heavy vehicles in Texas to demonstrate and evaluate the use of commercial technologies on military vehicles...CWS facilitated avoidance of $10 \mathrm{ac}-$ cidents in the 15,000 miles of convoy driving (p. 18)." This operational testing also supported the importance of training; drivers should understand the system, be trained on it, and know when to deactivate it. The 2001 report went on to describe that in fiscal year 1996, the Army added CWS to several high-convoy-use tactical vehicles, and later reported a 30\% decrease in convoy crashes (National Transportation Safety Board, 2001, p. 34). The military should examine the impact of CWS on crash rates since 1996 involving these vehicles, in order to assess the effectiveness of this type of crash-prevention technology.

The IIHS has determined that forward CWS could be relevant to more than 2 million frontal crashes that occur annually to civilian drivers. This technology is designed to provide drivers with an alert to allow sufficient time to avoid a crash, and is currently available on several cars (Insurance Institute for Highway Safety, 2008; National Transportation Safety Board, 2001). This analysis documented that collisions to the front of military vehicles were very common and CWS could prevent a large number of military crashes. A military work group (Rice, 2008) explored forward collision warning technology and recognized its strong potential to prevent a significant number of crashes. To address rear impact scenarios where a vehicle backs into a stationary object or vehicle, other technologies such as rear cameras/sensors and back-up beepers have also been assessed (Insurance Institute for Highway Safety, 2008; National Highway Traffic Safety Administration, 2011). These technologies were considered as part of rear-end collision avoidance for this study. Some of these features are included as part of technology designed to enhance driver vision, and back-up beepers have been integrated into military vehicles (Oak Ridge National Laboratory, 2001; Rice, 2008).

Emergency brake assistance could have been useful in several instances where the driver did brake for hazards, but could not stop in time to avoid crashing. This technology is being introduced on some high-end vehicles on the market (e.g., Rolls Royce) and senses panic braking (Insurance Institute for Highway Safety, 2008). There is some overlap with this technology and the CWS, and in this study, there were several crash events where both the forward collision warning and emergency brake assistance were selected. The military work group previously mentioned (Rice, 2008) did not assess this specific technology; however, it may be useful especially as technology to sense panic braking is available on the market.

Stability control systems were also evaluated by the military and the potential for implementation was rated as strong (Rice, 2008). This technology is particularly useful to prevent skidding and rollovers; these circumstances were frequently mentioned in the $20 \%$ of the narratives that described rollover scenarios. IIHS testing data reported that electronic stability control technology/rollover stability control could potentially lead to a 59\% reduction in SUV crashes (Insurance Institute for Highway Safety, 2006, p. 3). Similar reductions in rollovers may be achieved by implementing this technology on military vehicles.

Questions remain about the feasibility of implementing these technologies on military vehicles. In this study we did not explore how difficult it would be to install these technologies on military vehicles. Our review of the literature showed that these technologies have primarily been tested on luxury vehicles, except for rollover stability technology which has been tested on standard utility vehicles. Thus, there should also be particular attention to technology integration for both existing vehicles and newly developed vehicles, and further analysis to assess feasibility. Moreover, it may be more cost-effective to implement some of these technologies during the design stage, rather than having to retrofit vehicles, and economic analysis should be included to determine the cost/benefit and potential return-on-investment of these technologies. In addition, since human factors are essential in the use of these technologies, future research should also evaluate how individuals are using these technologies in practice.

This research examined MVCs involving military vehicles, an area that has received little attention in the peer-reviewed literature, therefore filling an important knowledge gap. However, there are some limitations of this study to consider. Although this descriptive study generated important information, it did not explore potential cofounding variables using multivariate models, which would have further elucidated crash causes. The data included in this report were provided by the U.S. Army Combat Readiness/Safety Center, and thus are subject to limitations of their data collection. For instance, despite regulations requiring accident reporting, the accident reporting system is passive and relies on leadership and enforcement. 
As a result, these data may underestimate the true magnitude of military vehicle crashes. Furthermore, rate calculations were impossible due to data limitations, thus these descriptive analyses relied on frequencies. Improvements in coding and data collection would be helpful for future research, which would include rate calculations. Although data abstracters received standardized training, these data may be limited due to the degree of subjectivity that was used by each of the data abstractors. Finally, approximately $93 \%$ of the crashes involved an Army motor vehicle; by aggregating vehicles into large categories, recommendations for specific vehicles could not be made.

\section{Summary and impact on industry}

These results are significant in light of ongoing global military operations that rely on military vehicles. Improving crash avoidance/preventive technology featured on military vehicles is one strategy that may help to reduce the occurrence of military crashes when combined with a comprehensive vehicle crash prevention program that concurrently addresses human factors and monitors motor vehicle crash-related trends.

\section{References}

Angello, J. J., \& Smith, J. K. (2010). The military accident and injury prevention challenge. Setting a foundation for the future. American Journal of Preventive Medicine, 38(1S), S212-S213.

Armed Forces Health Surveillance Center (2011). Motorcycle and other motor vehicle accident-related deaths, U.S. Armed Forces, 1999-2010. Medical Surveillance Monthly Report, 18(3), 2-5.

Dada, E., Canham-Chervak, M., \& Jones, B. H. (2010). Analysis of non-fatal motor vehiclerelated injuries captured in the Defense Medical Surveillance System (unpublished). U.S. Army Public Health Command, Aberdeen Proving Ground, MD.

Dada-Laseinde, E., Canham-Chervak, M., \& Jones, B. H. (2009). U.S. Army Annual Injury Epidemiology Report 2008 (Report No. 12-HF-OAPLa -09). Aberdeen Proving Ground, MD: U.S. Army Public Health Command.

Department of the Army (1994). Army Regulation 385-40: Accident Reporting and Records. Washington, D.C.: U.S. Government Printing Office.

Hanna W.B. (2007). Delphi. Oral presentation to Department of Defense Safety Policy Council (September 14).

Insurance Institute for Highway Safety (2006). Update on Two Effective Safety Features. Status Report, 41(5) (Retrieved from http://www.iihs.org/externaldata/srdata/docs/ sr4105.pdf)

Insurance Institute for Highway Safety (2008). Crash Avoidance Potential of Five Vehicle Technologies. Washington, DC: Farmer, C.M.

Jones, B. H., Canham-Chervak, M., Canada, S., Mitchener, T. A., \& Moore, S. (2010). Medical surveillance of injury in the U.S. Military. American Journal of Preventive Medicine, 38(1S), S42-S60.

Krahl, P. L., Jankosky, C. J., Thomas, R. J., \& Hooper, T. I. (2010). Systematic review of military motor vehicle crash-related injuries. American Journal of Preventive Medicine, 38(1), S189-S196

Lincoln, A. E., Sorock, G. S., Courtney, T. K., Wellman, H. M., Smith, G. S., \& Amoroso, P. J (2004). Using narrative text and coded data to develop hazard scenarios for occupational injury prevention. Injury Prevention, 10, 249-254.

McKenzie, K., Scott, D. A., Campbell, M. A., \& McClure, R. J. (2010). The use of narrative test for injury surveillance research: A systematic review. Accounts of Chemical Re search, 42, 354-363.

National Highway Traffic Safety Administration (2011). Crash Avoidance Research Program. Retrieved from http://www.nhtsa.gov/Research/Crash+Avoidance/Crash+ Avoidance+Research+Program

National Transportation Safety Board (2001). Vehicle- and infrastructure-based technology for the prevention of rear-end collisions (Special investigation report NTSB/SIR-01/01) Springfield, VA: National Technical Information Service.
Oak Ridge National Laboratory (2001). ITS Technologies in Military Wheeled Tactical Vehicles: Status Quo and the Future. Oak Ridge, TN: Knee, H.E., Gorsich, D.J. \& Kozera, M.J.

Oesch, S. T. (2009). Emerging vehicle safety issues. Statement from the Insurance Institute for Highway Safety before the U.S. Washington, DC: House Committee on Energy and Commerce, Subcommittee on Commerce, Trade, and Consumer Protection.

Rice, A. (2008). Assessment of Safety Technologies for Application in Tactical Vehicles. Washington, DC: Joint Military Vehicle Safety Working Group (JMVSWG).

Rossen, L. M., Pollack, K. M., Canham-Chervak, M., Canada, S., \& Baker, S. P. (2011). Motor Vehicle Crashes Among Active Duty Army Personnel from 1999 to 2006. Military Medicine, 176(9), 1019-1026.

SurveyMonkey (2011). Online Survey Database. Available from http://www.surveymonkey. com

Keshia M. Pollack, PhD, MPH is on faculty at the Johns Hopkins Bloomberg School of Public Health, where she is Director of the Johns Hopkins Doctoral Training in Occupational Injury Epidemiology and Prevention Program. She earned an MPH in chronic disease epidemiology from Yale University and a PhD from the Department of Health Policy and Management from Johns Hopkins Bloomberg School of Public Health. She is an expert in injury epidemiology and policy, and her work focuses on creating safe and health environments where people live, work, and play. She has conducted research on a variety of injury topics related to motor vehicle crashes, occupation, sports, pedestrians, bicyclists, and playgrounds.

Nathan Yee, BA graduated from Johns Hopkins University with a BA in Public Health. He subsequently went on to work at the Johns Hopkins Center for Injury Research and Policy where he collaborated on and contributed to various projects related to residential fire policy and vehicle safety. Nathan is currently a graduate student at the University of California School of Medicine and in the future aims to evaluate the intersection between public health and medicine specifically in relation to avoidable injury and safety in healthcare environments.

Michelle Canham-Chervak, PhD, MPH earned an MPH from Yale University and a PhD from Johns Hopkins Bloomberg School of Public Health. Prior employment includes internships with the National Institute for Occupational Safety and Health, the National Center for Health Statistics, and the Vermont Department of Health. Dr. Chervak is currently a senior epidemiologist in the Injury Prevention Program, U.S. Army Institute of Public Health (AIPH). Her work has focused on prevention of injuries related to motor vehicle crashes, falls, physical training, and sports and has ranged from field investigations of injury risk factors in Army populations, to evaluations of injury prevention programs, to the use of surveillance data in setting data-driven Army and DoD injury priorities. Dr. Chervak now also manages AIPH activities contributing to the Army's Soldier Medical Readiness Campaign Plan.

Kathleen Bachynski. MPH is a PhD student in sociomedical sciences at Columbia University's Mailman School of Public Health. She earned an MPH in epidemiology from the University of Michigan in Ann Arbor. She previously worked at the Veterans Affairs Ann Arbor Healthcare System and at the U.S. Army Public Health Command's Injury Prevention Program. She has studied DNA testing for colorectal cancer, suicide in the U.S. military, motor vehicle collisions, tobacco control policies, and sportsrelated injuries.

Lauren Rossen, $\mathrm{PhD}$, MS obtained her PhD in Health Policy and Management at the Johns Hopkins Bloomberg School of Public Health, and a Master's in Clinical and Health Psychology from the University of Florida. Her research has focused on a variety of topics related to health promotion and chronic disease prevention including: obesity, health behaviors, injuries, and social determinants of health. She is currently a postdoctoral fellow with the Office of Analysis and Epidemiology at the National Center for Health Statistics.

Susan P. Baker, MPH is an injury epidemiologist and professor at the Johns Hopkins Bloomberg School of Public Health. She received a BS at Cornell, an MPH at Johns Hopkins Bloomberg School of Public Health, and an honorary ScD from the University of North Carolina at Chapel Hill. Her research topics include injuries to motor vehicle occupants, pedestrians, and motorcyclists as well as airplane crashes, poisoning, and drowning. She developed the Injury Severity Score for describing injury severity in patients who sustain multiple injuries, and is working with surgeons evaluating factors related to trauma outcomes. 